\title{
Network Modeling of Biological Treatment Complex of Polymer Production Waste Water
}

\author{
Azimov Yu. I. ${ }^{1} \&$ Savdur S. N. ${ }^{1}$ \\ ${ }^{1}$ Institute of Management, Economics and Finance, Kazan Federal University, Kazan, 420008, Russia \\ Correspondence: Savdur S. N., Institute of Management, Economics and Finance, Kazan Federal University, \\ Kazan, 420008, Russia. Tel: 7-904-764-7578. E-mail: savdur.svetlana@yandex.ru
}

Received: December 27, 2014 Accepted: February 19, 2015 Online Published: April 30, 2015

doi:10.5539/ass.v11n11p50

URL: http://dx.doi.org/10.5539/ass.v11n11p50

\begin{abstract}
The article discusses technological complex of biochemical wastewater treatment (BWWT) of polymer production. Based on the review of the main methods of modeling discrete-continuous biochemist technology systems (BCTS) it substantiates the appropriateness of applying the of Petri nets (PN) theory for modeling BWWT of polymer industries. It is proposed to use a modification of Petri nets that focuses on modeling and analysis of discrete-continuous BCTS, by introducing priority transitions, deterministic time delays for transitions and places. A model in the form of a modified Petri net (MPN) is constructed. By means of SCADA TRACE MODE, software package to control BWWT technology system is designed.
\end{abstract}

Keywords: modified Petri nets, biochemical wastewater treatment of polymer production, the modeled system, a biochemical and technological system, computer simulation

\section{Introduction}

Modern production lines of BWWT have a complex multi-layered structure, therefore, they can be considered as complex cybernetic systems. When studying them, the strategy of system analysis is used. Given the task complexity of modeling and analysis of such systems it is necessary to apply modern methods of mathematical and computer modeling.

\section{Materials and Methods}

In solving the problems set up in the study, the methods of systems analysis, computer modeling, Petri nets theory, graph theory were used.

\section{Theory}

Manufacturing process for the polymer product is associated with significant quantities of waste water, which is a multi constituent system containing dissolved inorganic (e.g. sodium sulphate) or organic (hide glue, dextrin, nitro) substances. These constituents influence the environment and the human body and threaten poisoning, causing changes in the excitatory system, and having a slightly irritant action. Such wastewater cannot be discharged without treatment into the pond beyond the perimeter of the enterprise. The prerequisite for preserving the ecological balance of the environment is integrated wastewater treatment.

Wastewater of polymer production is usually cleaned of their contents in the catchalls, water boots, labyrinths, filters, and then it is discharged as conditionally pure. Especially toxic substances are subjected to thermal and chemical methods of destruction. However, plants and methods being used currently are not always effective. Biochemical treatment is the most economical and reliable sewage treatment where living organisms play a leading part (bacteria, microorganisms, protozoa, etc.).

Modern treatment facilities of large chemical enterprises are structurally complex systems. Therefore, of considerable interest are the conditions for their emergency operation in which waste water has dynamically varying parameters both by composition and by flow rate up to the volley of sewage indicators (Fesina \& Savdur, 2014). The efficiency of such systems can be achieved by using modern methods of information processing, using the methods of complex objects system analysis based on the mathematical description of the process (Hunt, Timoshkina, Baudains, \& Bishop, 2012). 
In accordance with the principles of system analysis, BWWT industrial plant is a biochemist and technological system, which includes a set of interrelated material, thermal and information flow units, each of which has a hierarchical structure (Motameni, Movaghar, Shirazi, Aminzadeh, \& Samadi, 2008). BWWT can be divided into interconnected subsystems characterized by a hierarchical structure. Management tasks at each level of the production hierarchy are different, but the general objective is wastewater treatment to standard indicators or to provide recycling water supply level (Kadochnikova, 2013).

A main area of studying complex systems, which BWWT represents, is informational approach that is based on mathematical modeling of the object (Huilinir, Aspe, \& Roeckel, 2011). Modeling and computer experiments with model-replacement of an object are an effective means to create management systems, to consider the object's behavior in emergency situations, to evaluate its structure and control rules, as well as to take into account the stochastic nature of disturbances (Haroonabadi, Teshnehlab, \& Movaghar, 2008; Ruiz, Sin, Berjaga, Colprim, Puig, \& Colomer, 2011). There are two approaches to the modeling of real objects. In the first approach, the object is represented as a dynamic system with a continuous variable. This approach is widely used in modeling chemical and technological processes with continuous organization of processes (Peter, 1976; Buswell $\&$ Mueller, 1952) provided its stationarity and the invariableness of physical and chemical parameters. In the second approach, the object is represented as a dynamic system with discrete events (DSDE). These include manufacturing systems, assembly lines, computer networks.

DSDE class also includes discrete-continuous biochemist technology systems. Solving the problem of managing such discrete dynamical systems requires the use of special mathematical methods. Traditionally for this purpose the state machine approach, logical-linguistic and simulation modeling are used, as well as of the theory of graphs and networks, PN (Ismagilov, 2006). Comparative analysis as the primary unit of mathematical modeling enables to select the PN theory (Ismagilov, 2006). PN assumes to simulate discrete parallel asynchronous processes (Ismagilov, 2006), to get a graphical representation of the network, to describe the system at different abstraction levels, to present the system hierarchy (Zhou \& Li, 2010), to analyze models using modern software packages.

\section{Results}

Applying the methods of system analysis lets to develop a control system of biotreatment plants of process effluent from polymer production (Figure 1), which provides for the construction of a mathematical model based on the PN.

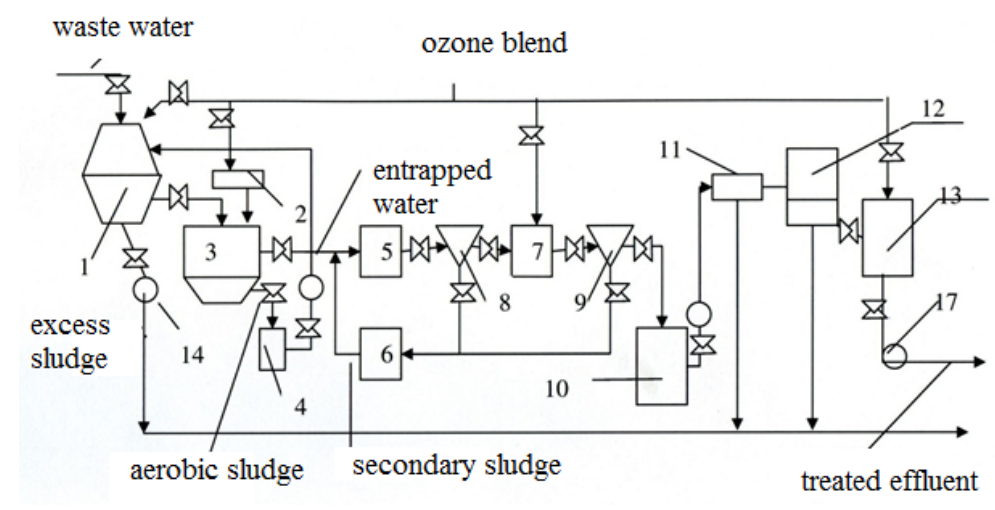

Figure 1. Process flow diagram of effluent treatment

1 - digester; 2 - ozonizer; 3 - settler-clarifier; 4 - container; 5 - aerotank of stage 1; 6 - regenerator; 7 - aerotank of stage 2; 8 - primary settler; 9 - secondary settler; 10 - receiving tank; 11 - microfilter; 12 - filter with grit; 13 contact tank; 14-17 - pumps.

To describe the system, we propose to use $\mathrm{N}$-schemes, based on the mathematical apparatus of Petri nets, whose advantage is possible representation of the network model both in analytical form, automating the process of analysis, and in graphical form providing visualization of the model developed.

When analyzing chemical-technological or a biochemical process flow diagrams one should consider the main limitation of the $\mathrm{N}$-scheme formalism, which consists in the fact that they do not account for the time characteristics of the simulated systems, since the enabling time of the transition is considered to be zero. Given these conditions, we have proposed the modified Petri net. MPN - Petri net of the form $\mathrm{C}=<\mathrm{P}, \mathrm{T}, \mathrm{I}, \mathrm{O}, \mathrm{M}, \mathrm{L}, \tau_{1}, \tau_{2}>$ 
Where $\mathrm{T}=\left\{\mathrm{t}_{\mathrm{j}}\right\}$ - finite empty set of symbols called transitions are measured depending on the number of conventional product portions with a continuous feeding to apparatus in the process flow.

$\mathrm{P}=\left\{\mathrm{p}_{\mathrm{i}}\right\}$ - finite empty set of symbols called positions. In our case - a set of process flow devices.

$\mathrm{I}: \mathrm{PxT} \rightarrow\{0,1\}$ - input function, which for each $\mathrm{t}_{\mathrm{i}}$ transition gives the set its position $\mathrm{p}_{\mathrm{i}} \in \mathrm{I}\left(\mathrm{t}_{\mathrm{j}}\right)$.

About: PxT $\rightarrow\{0,1\}$ - the output function, which reflects a transition to the set of output positions $\mathrm{p}_{\mathrm{i}} \in \mathrm{O}\left(\mathrm{t}_{\mathrm{j}}\right)$.

Thus, for each transition it is possible to determine the set of input position $I\left(t_{j}\right)$ and the output position $O\left(t_{j}\right)$ as:

$$
\mathrm{I}\left(\mathrm{t}_{\mathrm{j}}\right)=\left\{\mathrm{p}_{\mathrm{i}} \in \mathrm{P} / \mathrm{I}\left(\mathrm{p}_{\mathrm{i}}, \mathrm{t}_{\mathrm{j}}\right)=1\right\} ; \mathrm{O}\left(\mathrm{t}_{\mathrm{j}}\right)=\left\{\mathrm{pi} \in \mathrm{P} / \mathrm{O}\left(\mathrm{p}_{\mathrm{i}}, \mathrm{t}_{\mathrm{j}}\right)=1\right\}
$$

$\mathrm{M}: \mathrm{P} \rightarrow\{1,2,3, \ldots\}$-marking of net which assigns a non-negative integer to each position which is equal to the number of marking in a given position, which varies during the operation of the net.

Enabling the transition instantaneously changes the marking $(p)=\left(M\left(p_{1}\right), M\left(p_{2}\right), M\left(p_{3}\right) \ldots M\left(p_{n}\right)\right)$ for marking $\mathrm{M}^{\prime}(\mathrm{p})$ by the following rule:

$$
\mathrm{M}^{\prime}(\mathrm{p})=\mathrm{M}(\mathrm{p})-\mathrm{I}\left(\mathrm{t}_{\mathrm{j}}\right)+\mathrm{O}\left(\mathrm{t}_{\mathrm{j}}\right)
$$

Equation (2) means that the transition $t_{j}$ subducts one marking from the position of each of its input and adds one marking to each of the outputs.

$\tau_{1}: \mathrm{T} \rightarrow \mathrm{N} \quad$ и $\tau_{2}: \mathrm{P} \rightarrow \mathrm{N}$ functions determining the time delay when enabling transition and the delay time in the position.

The dynamics of MPN is determined by marking movement which simulates discrete flow balance of preproduct in the defined limits by the volume of BWWT plants.

The real state of individual apparatus (positions) for the chemical-technological production (CTP) in analytical and graphical form may be presented in Table 1 .

Table 1. The state of individual apparatus (positions) for the chemical-technological production in analytical and graphical form

$$
\text { Process scheme of apparatus }
$$

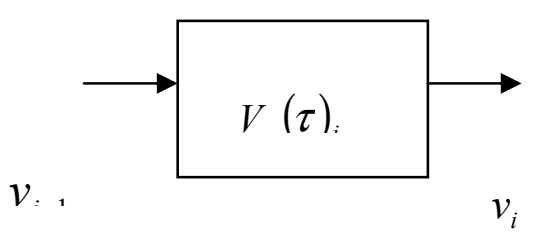

where $v_{i-1}, v_{i}$ - volume flow rate at entrance and exit of $i$-th apparatus $\left(\mathrm{m}^{3} / \mathrm{sec}\right)$;

$V(\tau)_{i}, V_{0 i}-$ full and current volume of $i-$ th apparatus $\left(\mathrm{m}^{3}\right)$.

$I\left(t_{i}\right)=v_{i-1} \Delta \tau$

$O\left(t_{i}\right)=v_{i} \Delta \tau$

$V(\tau)_{i} \leq V_{0 i}$

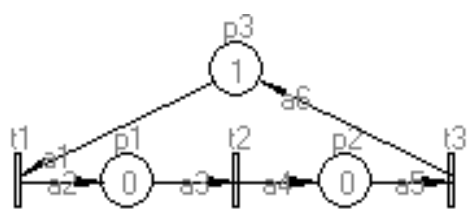

p1 - position which informs about current volume of preproduct portions in the apparatus;

$\mathrm{M}(\mathrm{p} 1)=V_{0 i} ;$

p2 - position which informs about current volume of the portion processed in the apparatus;

p3 - position which informs about space in the apparatus;

$$
\mathrm{M}(\mathrm{p} 2)=V_{0 i}-V(\tau)_{i} ;
$$

t1 - transition modelling preproduct portion charge in the apparatus;

t2 - transition which models processing of the portion charged;

t3 - transition which models discharge of the portion processed. 
PN modification considered allows to analyze the functioning of the system devices in emergency, the switching control at the network level, and flow charts of discrete - continuous production for sustainable, stable system state.

To control BWWT process, a mathematical model of the technological scheme and its software implementation was developed. A mathematical model of the BWWT system is designed in the form of MPN, whose implementation will help to investigate system communications and the rules for unit functioning as a whole. Models of basic devices are also constructed, they implement BWWT process (Barzegar \& Motameni, 2011). Model of the entire plant was synthesized from PN models of typical apparatus (Figure 2).

Using the PN-model, software of BWWT process module, simulating the operation of bio-treatment in virtual time was developed. Software package for BWWT process control system was developed with the means of SCADA TRACE MODE (Albert, Yao, Ji, \& Liao, 2010). The process control system allows supervisory control of the main elements of the management system, to stop BWWT system and analyze its state as a whole, and to predict the development of emergency situations. (Albert, Yao, Ji, \& Liao, 2010)

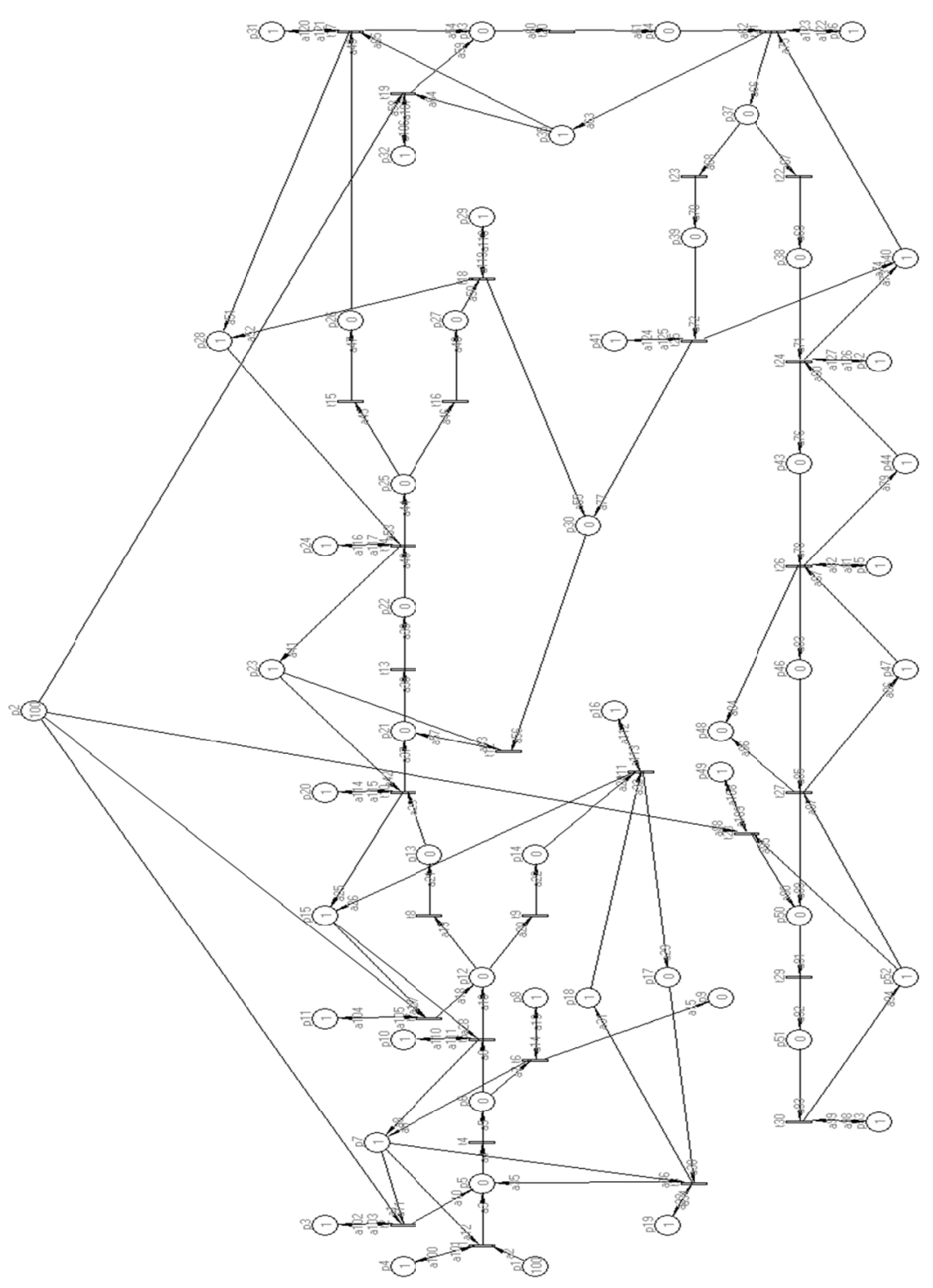

Figure 2. A general Petri net of biochemical sewage treatment plant of polymer production 


\section{Conclusions}

When analyzing chemical-engineering (a biochemical process) systems, the basic limitation of N-schemes formalism is established, it is in the fact that $\mathrm{N}$-schemes do not consider time characteristics of the simulated systems. This necessitates the use of PN modification focused on modeling and analysis of discrete-continuous BCTS by introducing priority transitions, deterministic time delays for transitions and places. Constructing mathematical models of systems functioning of effluent biotreatment process of polymer production in the form of modified Petri nets, allows us to study the system communications and the rules for entire system functioning. The developed software of BWWT systems enables to analyze the state of the biotreatment system as a whole and to predict the development of emergency situations.

\section{References}

Fesina, E., \& Savdur, S. (2014). Modeling of Sewage Bioremediation as a Modified Petri Net. World Applied Sciences Journal, 31(6), 1191-1197.

Hunt, J. C. R., Timoshkina, Y., Baudains, P. J, \& Bishop, S. R. (2012). System Dynamics Applied to Operations and Policy Decisions. European Review, 20(3), 324-342.

Motameni, H., Movaghar, A., Shirazi, B., Aminzadeh, M., \& Samadi, H. (2008). Analysis Software with an Object-Oriented Petri Net Model. World Applied Sciences Journal, 3(4), 565-576.

Kadochnikova, E. (2013). Methodological Issues of Macroeconomic Accounting (Review). World Applied Sciences Journal, 24(6), 719-723.

Huilinir, C., Aspe, E., \& Roeckel, M. (2011). Modeling of the denitrification/anaerobic digestion process of salmon fishery wastewater in a biofilm tubular reactor. Journal of Environmental Management, 92, 1591-1608.

Haroonabadi, A., Teshnehlab, M., \& Movaghar, A. (2008). A Novel Method for Behavior Modeling in Uncertain Information Systems. World Applied Sciences Journal, 3(5), 797-805.

Ruiz, M., Sin, G., Berjaga, X., Colprim, J., Puig, S., \& Colomer, J. (2011). Multivariate Principal Component Analysis and Case-Based Reasoning for monitoring, fault detection and diagnosis in a WWTP. Water Science, Technology, 64(8), 1661-1667.

Peter, P. (1976). Determination of Biological Degradability of Organic Substrates. Water Research, 10, 231-235.

Buswell, A. M., \& Mueller, M. F. (1952). Mechanisms of Methane Fermentation. Industrial and Engineering Chemistry, 44, 550-552.

Ismagilov, I. I. (2006). An approach to ordering of systems of the Walsh discrete functions. Radioelectronics and Communications Systems, 49(1), 46-50.

Zhou, M. C., \& Li, Z. W. (2010). Special issue on "Petri nets for system control and automation". Asian Journal of Control, 12(3), 237-239.

Barzegar, B., \& Motameni, H. (2011). Modeling and Simulation Firewall Using Colored Petri Net. World Applied Sciences Journal, 15(6), 826-830.

Albert, W., Yao, L., Ji, Z. M., \& Liao, H. T. (2010). A Petri nets-based process planning system for wastewater treatment. Asian Journal of Control, 12(3), 281-291.

Nasby, G., \& Phillips, M. (2011). SCADA standardization: Modernization of a municipal waterworks with SCADA standardization: Past, present, and planning for the future. InTech, 58(5-6), 1.

Ankudinov, B., \& Lebedev, O. V. (2014). Job insecurity and employees' motivation to engage in professional education. American Journal of Applied Sciences, 11(5), 860-865.

Ismagilov, I. I. (2010). Oblique generalizations of the Walsh basis. Radioelectronics and Communications Systems, 53(12), 625-635.

\section{Copyrights}

Copyright for this article is retained by the author(s), with first publication rights granted to the journal.

This is an open-access article distributed under the terms and conditions of the Creative Commons Attribution license (http://creativecommons.org/licenses/by/3.0/). 